\title{
Overview of technical solutions and assessment of clinical usefulness of capsule endoscopy
}

\author{
Robert Koprowski
}

*Correspondence:

koprow@us.edu.pl

Department of Biomedical

Computer Systems, Faculty

of Computer Science

and Materials Science,

Institute of Computer

Science, University

of Silesia, ul. Będzińska 39,

41-200 Sosnowiec, Poland

\begin{abstract}
The paper presents an overview of endoscopic capsules with particular emphasis on technical aspects. It indicates common problems in capsule endoscopy such as: (1) limited wireless communication (2) the use of capsule endoscopy in the case of partial patency of the gastrointestinal tract, (3) limited imaging area, (4) external capsule control limitations. It also presents the prospects of capsule endoscopy, the most recent technical solutions for biopsy and the mobility of the capsule in the gastrointestinal tract. The paper shows the possibilities of increasing clinical usefulness of capsule endoscopy resulting from technological limitations. Attention has also been paid to the current role of capsule endoscopy in screening tests and the limitations of its effectiveness. The paper includes the author's recommendations concerning the direction of further research and the possibility of enhancing the scope of capsule endoscopy.
\end{abstract}

Keywords: Biomedical, Capsule, CCD, CMOS, Image processing, Medical image, PillCam, SB2

\section{Background}

Capsule endoscopy is a technique known for many years which enables to watch the mucosa of the small intestine, large intestine and oesophageal. It involves swallowing a capsule and on-line or off-line data transmission to a receiver or computer. Using this technique, it is possible to access the small intestine and diagnose different types of diseases which are difficult to diagnose by means of other methods (classic endoscopy with the use of a flexible tube). These diseases include: (1) chronic gastrointestinal bleeding; (2) unexplained iron deficiency anaemia; (3) Crohn's disease; (4) tumour of the small intestine; (5) damage to the mucosa of the small intestine; (6) celiac disease; (7) gastrointestinal polyposis syndromes. Moreover, there are few restrictions on the use of capsule endoscopy. Contraindications include: (1) narrowing and obstruction of the gastrointestinal tract; (2) dysphagia; (3) disorders of gastrointestinal motility; (4) intestinal fistula; (5) multiple or large gastrointestinal diverticula; (6) abdominal surgeries; (7) pregnancy; (8) a heart pacemaker. With so few contraindications, gastrointestinal diagnostics using capsule endoscopy is very popular and, as a result, it is being rapidly developed. This is evidenced by a number of research papers published worldwide. The details of these papers are described in the following subsections.

(c) 2015 Koprowski. This article is distributed under the terms of the Creative Commons Attribution 4.0 International License (http:// creativecommons.org/licenses/by/4.0/), which permits unrestricted use, distribution, and reproduction in any medium, provided you give appropriate credit to the original author(s) and the source, provide a link to the Creative Commons license, and indicate if changes were made. The Creative Commons Public Domain Dedication waiver (http://creativecommons.org/publicdomain/ zero/1.0/) applies to the data made available in this article, unless otherwise stated. 


\section{State of the art associated with endoscopy: a review of articles}

At the time of writing this paper there were 4234 articles containing the word "Capsule Endoscopy" according to the data published on AuthorMapper. A similar number of articles are available on PubMed-3488 articles. The number of articles published per country is shown in Table 1. It should be emphasized that the number of papers given on AuthorMapper is sometimes inflated by multiple counting of the same work. Thematic areas with the greatest number of articles are: Medicine \& Public Health-3201 articles (e.g. [36]), Gastroenterology-1608 articles (e.g. [37]), Hepatology-875 articles ([38]), Oncology and Surgery-763 and 744 articles respectively $([39,40])$. As shown in Table 1 and above, the area of research devoted to capsule endoscopy is essentially associated with medicine. The known review articles related to capsule endoscopy and its use in medicine also deal with this area. For example, these are works [31] or [32]. In the Web of Science database it is possible to trace publications which have the largest number of citations or are the most influential. The first authors with the greatest number of citations are: Iddan [41] 1101 citations, Costamagna [42] 557 citations, Pennazio [43] 510 citations and then Ell C. [44] and Lewis [45] 471 and 360 citations respectively. The first mentioned author, Iddan G, is the inventor of capsule endoscopy. He was inspired by the 1966 film "Fantastic Voyage" about a trip to the interior of the body. The other authors present new approaches to the use of capsule endoscopy.

The information given in Table 1 and above summarizes the state of capsule endoscopy in the world. The thematic division of articles on capsule endoscopy where the area of medicine and public health comes first is particularly noteworthy. Moreover, it should be noted that the areas of microbiotics or computer science, necessary to program the internal capsule control, are not present in the tables. The areas of hepatology and oncology, in which 875 and 763 articles respectively are on the use of capsule endoscopy, are also of interest. The authors listed above deal with biomedical engineering (Iddan G.) and medical diagnostics (Costamagna G., Pennazio M., Ell C., Lewis B.). The direction of research that largely focuses on clinical applications and to a lesser extent (almost

Table 1 Comparison of the number of articles containing the word "capsule endoscopy" per countries, institutions and authors as at 06.02.2015 (only the first five are provided)

\begin{tabular}{llcc}
\hline Characteristic & Units/authors & Number of articles & Examples \\
\hline Country & United States & 1484 & {$[1-3]$} \\
& Germany & 323 & {$[4-6]$} \\
& Japan & 322 & {$[7-9]$} \\
& Italy & 297 & {$[10-12]$} \\
& United Kingdom & 241 & {$[13-15]$} \\
& Columbia University & 364 & {$[16-18]$} \\
Institution & Mayo Clinic & 49 & {$[3,19-21]$} \\
& University of Amsterdam & 26 & {$[22-24]$} \\
& Kyushu University & 23 & {$[25-27]$} \\
& Harvard Medical School & 21 & {$[28-30]$} \\
& Minc N. & 358 & {$[31]$} \\
Author & Packer C. & 46 & {$[32]$} \\
& Dijk C. & 19 & {$[33]$} \\
& Lui T. H. & 15 & {$[34]$} \\
& Wang Z. & 15 & {$[35]$} \\
\hline
\end{tabular}


residual) relates to new developments and electro-technical [46, 47] modifications of endoscopic capsules is equally interesting. The consequence is also a limited number of citations of articles related to technical descriptions of new solutions.

The works on micro-robotics are slightly different, and also the number of granted patents for capsule endoscopy differs. In the database of google patents there are 3530 patent descriptions containing the word "capsule endoscopy". However, most of the solutions require additional equipment (data capture systems or systems controlling the capsule route) and not individual innovative capsule solutions. Looking at both medicine and engineering, it seems that the former one is developing very well in terms of various types of applications and diagnostics using capsules. The majority of the aforementioned publications are devoted to this area. The technological development of endoscopic capsules looks far worse. Therefore this paper is devoted to the review of the state of the art with particular emphasis on practical clinical usefulness.

\section{Nomenclature used in the field of capsule endoscopy}

Particular attention should be paid here to the following distinction between five terms known from literature:

VCE: video capsule endoscopy — capsule endoscopy including an imaging device such as a CCD (not relating to endoscopic capsules devoid of an image sensor, the capsule does not have to be wireless);

WVE: wireless video endoscopy (not necessarily a capsule);

CE: capsule endoscopy-endoscopic capsule (not necessarily wireless);

WCE: wireless capsule endoscopy (not necessarily containing an image sensor);

WVC: wireless video capsule.

The distinction is presented in Fig. 1. In literature these terms are often confused and used interchangeably. Consequently, in this paper, they will be all referred to as "capsule endoscopy".

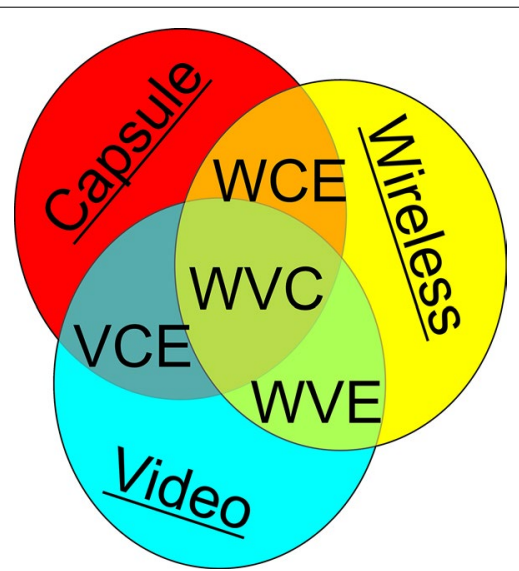

Fig. 1 Distinction of the nomenclature relating to capsules, wirelessness and video. Red shows the area covered by the definition "Capsule", yellow "Wireless" and blue "Video". The respective intersections of these areas (circles) refer to different types of endoscopy. WCE (video capsule endoscopy), VCE (wireless capsule endoscopy), WVE (wireless video endoscopy) when two areas intersect and WVC (wireless video capsule) when all three areas intersect 
Typical known endoscopic capsules that are currently used in medical diagnosis are presented below. The following section presents new types of endoscopic capsules representing the prospects and direction of development in the coming years.

\section{Typical, most common capsule solutions (standard techniques)}

The most popular capsule endoscopy systems consist of three elements: (a) a capsule swallowed by the patient; (b) a system for acquisition of wirelessly sent data; (c) a computer with software for analysing the recorded data. Details of the system are shown in Fig. 2. The system shown in Fig. 2 is a well-known capsule endoscopy system proposed by Iddan [41] and used to date. Its single elements evolve in line with advances in miniaturization in electronics and micro-robotics, finding more areas of clinical applications. The most popular endoscopic capsules along with characterization of the acquisition systems (number of antennas) are shown in Table 2. As is clear from the data provided in the summary in Table 2, capsules are divided in terms of their application and they can be used to diagnose: (1) the small intestine; (2) the large intestine; (3) the oesophagus. Depending on the application, they have different operating time, frequency of taking images and number of cameras. In the oesophagus diagnosis, two cameras, which are disposed on opposite sides of the capsule, are used due to the relatively short residence time of the capsule in the oesophagus, a high frequency of taking oesophagus images and short operating time. In the diagnosis of the small and large intestine, one camera and not too high frame rate are used (due to the need to save battery-the average residence time of the capsule in the small and large intestine is approximately $8 \mathrm{~h}$ ). In addition to the camera (cameras), typical capsules also contain other electronic components necessary for proper operation-Fig. 3. A typical endoscopic capsule consists of: a CCD

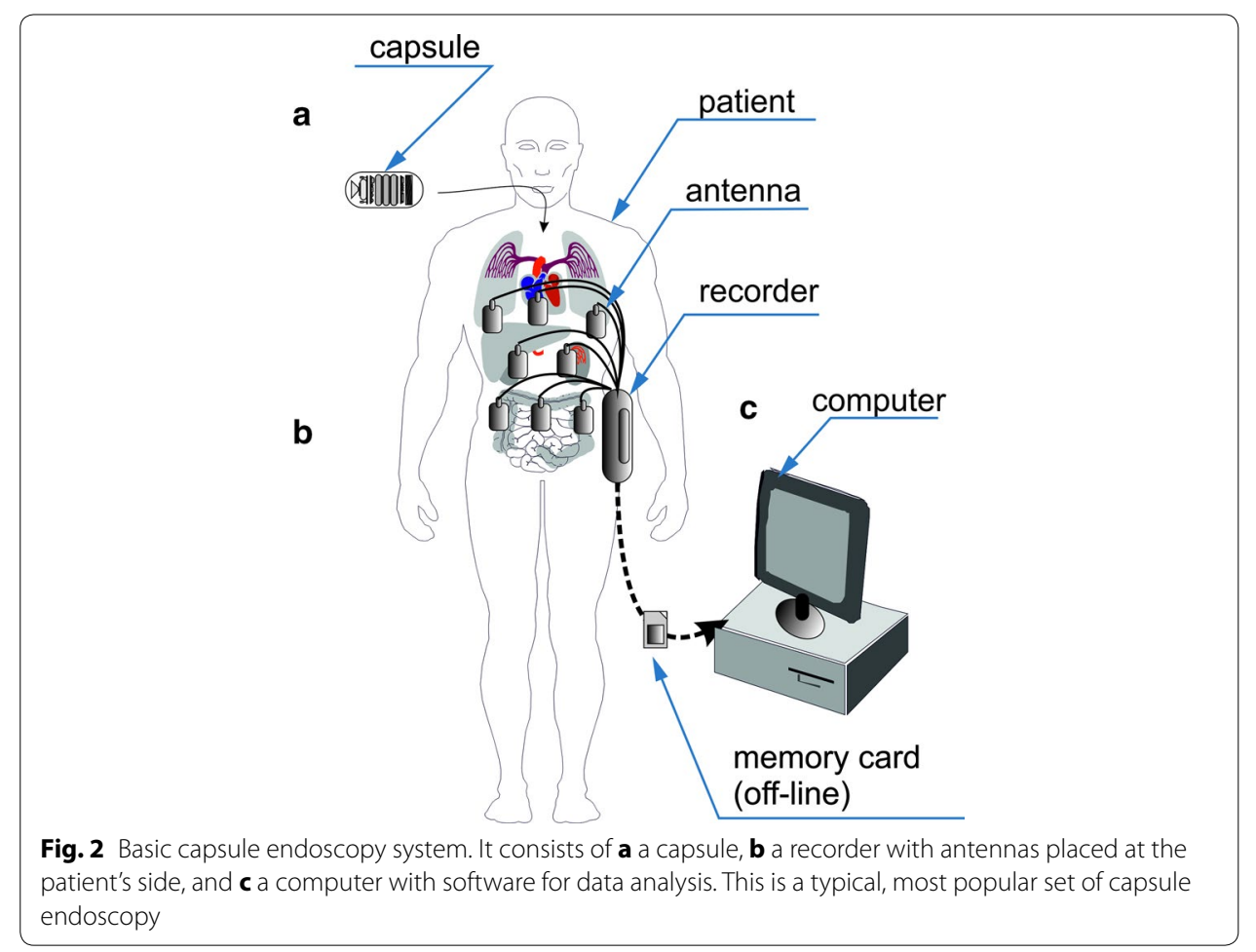


Table 2 Summary of the most popular endoscopic capsules and their basic parameters

\begin{tabular}{|c|c|c|c|c|c|c|c|c|}
\hline & \multicolumn{3}{|c|}{ Given imaging_Israel } & \multirow{2}{*}{$\begin{array}{l}\text { KIST- } \\
\text { Korea } \\
\text { Mirocam }\end{array}$} & \multirow{2}{*}{$\begin{array}{l}\text { Olympus- } \\
\text { Japan } \\
\text { Endocap- } \\
\text { sule }\end{array}$} & \multirow{2}{*}{$\begin{array}{l}\text { Jinshan- } \\
\text { China } \\
\text { OMOM }\end{array}$} & \multicolumn{2}{|c|}{$\begin{array}{l}\text { RF System Lab.- } \\
\text { Japan }\end{array}$} \\
\hline & Pillcam SB2 & Pillcam eso & $\begin{array}{l}\text { Pillcam } \\
\text { colon }\end{array}$ & & & & Norika 3 & Sayaka \\
\hline Length ( $\mathrm{mm}$ ) & ) 26 & 26 & 32 & 24 & 26 & 27.9 & 23 & 23 \\
\hline $\begin{array}{l}\text { Diameter } \\
(\mathrm{mm})\end{array}$ & 11 & 11 & 11.6 & 11 & 11 & 13 & 9 & 9 \\
\hline Weight (g) & 3.4 & 3.4 & 3.4 & 3.4 & 3.8 & 6 & - & - \\
\hline $\begin{array}{l}\text { Number of } \\
\text { cameras }\end{array}$ & 1 & 2 & 2 & 1 & 1 & 1 & 1 & 1 \\
\hline $\begin{array}{l}\text { Number of } \\
\text { frames per } \\
\text { second }\end{array}$ & 2 & 18 & $4-35$ & 3 & 2 & 2 & 30 & 30 \\
\hline Sensor & CMOS & CMOS & CMOS & $C C D$ & $C C D$ & $C C D$ & $C C D$ & $C C D$ \\
\hline $\begin{array}{l}\text { Operation } \\
\text { time }(h)\end{array}$ & 8 & $20 \mathrm{~m}$ & 10 & 11 & 9 & 8 & 8 & 8 \\
\hline $\begin{array}{l}\text { Number of } \\
\text { antennas }\end{array}$ & 8 & 3 & 8 & 9 & 8 & 14 & 8 & 8 \\
\hline $\begin{array}{l}\text { Snooze } \\
\text { option }\end{array}$ & No & No & Yes & No & No & No & Yes & Yes \\
\hline $\begin{array}{l}\text { Destina- } \\
\text { tion-the } \\
\text { test area }\end{array}$ & $\begin{array}{l}\text { Small (S) } \\
\text { intestine }\end{array}$ & Esophagus & $\begin{array}{l}\text { Large }(L) \\
\text { intestine }\end{array}$ & $\mathrm{S} / \mathrm{L}$ intestine & eS intestine & S intestine & S intestine & S intestine \\
\hline
\end{tabular}

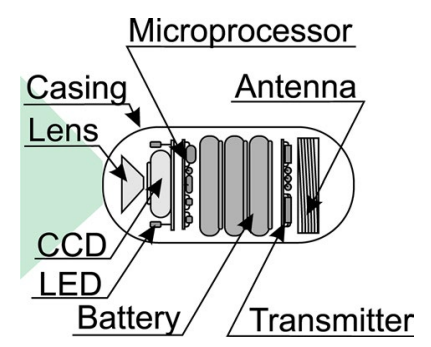

Fig. 3 Block diagram of a typical endoscopic capsule. The capsule contains: a lens with CCD, a set of LEDs illuminating the test area, microprocessor control, transmitter with antenna and power supply in the form of batteries

or a CMOS camera placed on its one or both sides providing images with a typical resolution of $320 \times 240$ pixels, a lens allowing for wide-field acquisitions $\left(170^{\circ}\right)$ of the visible intestine area, from 4 to 8 LEDs illuminating the imaging area in visible light, a battery consisting of two $1.5 \mathrm{~V}$ cells, a transmitter with an antenna that allows wireless communication with a receiver placed on the patient (Fig. 2). For a typical endoscopic capsule, the operating time is a few hours and significantly exceeds the needs-i.e. the average residence time of the capsule in the body. In practice, namely in clinical applications, there are two important aspects in these typical solutions: (1) battery life; (2) maximum distance of data transmission. In the first case, situations when capsules get stuck in the intestine and the possibility of observing the reasons for these situations are clinically vital. In the latter case, the convenience of the patient who has to wear the apparatus receiving the data sent by the capsule is important. A typical maximum distance of the 
receiver from the capsule is a few centimetres (for typical data transmission in the band $434 \mathrm{MHz}$ with a $267 \mathrm{~kb} / \mathrm{s}$ data rate). Data are transmitted unidirectionally (from the capsule to the receiver). After the acquisition, the storage medium (usually a memory card) is transferred manually to a computer where the data (images) are analysed using dedicated software. Typical software (e.g. CapsoView ${ }^{\mathrm{TM}} \mathrm{CVV}$ is CapsoVision's ver 1.0) enables to view the sequence of images stored in the form of a video, mark the selected pathological area and create reports. Clinically, the described known solutions of a capsule endoscopy system have drawbacks. These are:

- ensuring the patency of the gastrointestinal tract;

- wireless communication limitations;

- the ability to control the capsule position;

- a change of the imaging area;

- a reduction in the length of the capsule endoscopic video watched by a doctor.

For these reasons, capsule endoscopy technology is still being modified and improved. These drawbacks have been offset by using the following solutions.

\section{Ensuring the patency of the gastrointestinal tract}

In order to verify the patency of the gastrointestinal tract, a pilot capsule (Agile) is used for a typical size of the endoscopic capsule. This capsule has a typical size $(26 \times 11 \mathrm{~mm})$ and dissolves in the intestine after $30 \mathrm{~h}$ if it gets stuck. The pilot capsule in the previous version contained a thin marker ( $2 \mathrm{~mm}$ in diameter) and in the newer one a RFID (radio-frequency identification) tag of the same diameter. The pilot capsule, however, increases the total examination cost and extends the time of obtaining diagnostically relevant results.

\section{Limitations of wireless communication}

Regardless of the technological development, wireless data transmission still entails limitations. Therefore, in 2013 CapsoVision introduced the CapsoCam SV-1 shown in Fig. 4. The capsule presented in Fig. 4 has the following parameters: (1) viewing area-360 ; (2) the number of frames per second-20, (3) operating time-15 h; (4) data record-flash memory; (5) the size of $31 \times 11 \mathrm{~mm}$; (6) LED lighting -16; (7) the number of cameras-4; (8) motion sensor and LED brightness. Writing data directly in the flash memory has two drawbacks: (1) clinical-no possibility of observing the area being imaged on-line,

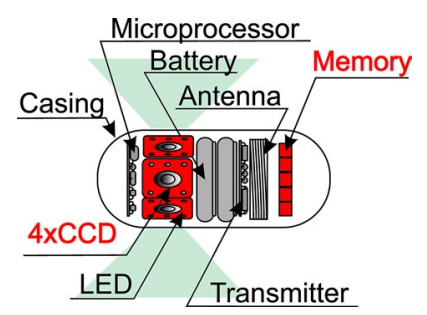

Fig. 4 CapsoCam SV-1 - block diagram. Red indicates changes compared to the original version of the capsule. There are four CCD cameras placed relative to each other at an angle of $90^{\circ}$ and a data memory 
(2) technical-the need for a special docking station that enables to access the memory and read data. The flash memory is one of the biggest advantages of this capsule allowing for complete elimination of the receiver and the need to transfer data wirelessly. In addition, this type of capsule has four cameras placed at an angle of $90^{\circ}$ relative to each other. This increases the area and fidelity of imaging-cameras are often arranged at right angles relative to the imaged area.

\section{Controlling the capsule position}

Controlling the position of the capsule is very important clinically because of the need for orientation and careful observation of characteristic, diagnostically interesting areas. This is done by using an electromagnetic field. The capsule has a permanent magnet and the external magnetic field is changed, or vice versa-Fig. 5. The coils of electromagnet placed inside the capsule (Fig. 5) are in three axes so that the capsule can perform virtually any motion. Despite the full freedom of movement (front/rear, left/right, up/down, rotation, side, attitude, jump), a diagnostician most often uses rotation [49]. This is due to the need for accurate viewing of the selected, diagnostically interesting area. In practice, however, the patented solution of the electromagnetic device placed on the patient [49] has not gained a foothold. To control the capsule, the same technique yet stationary

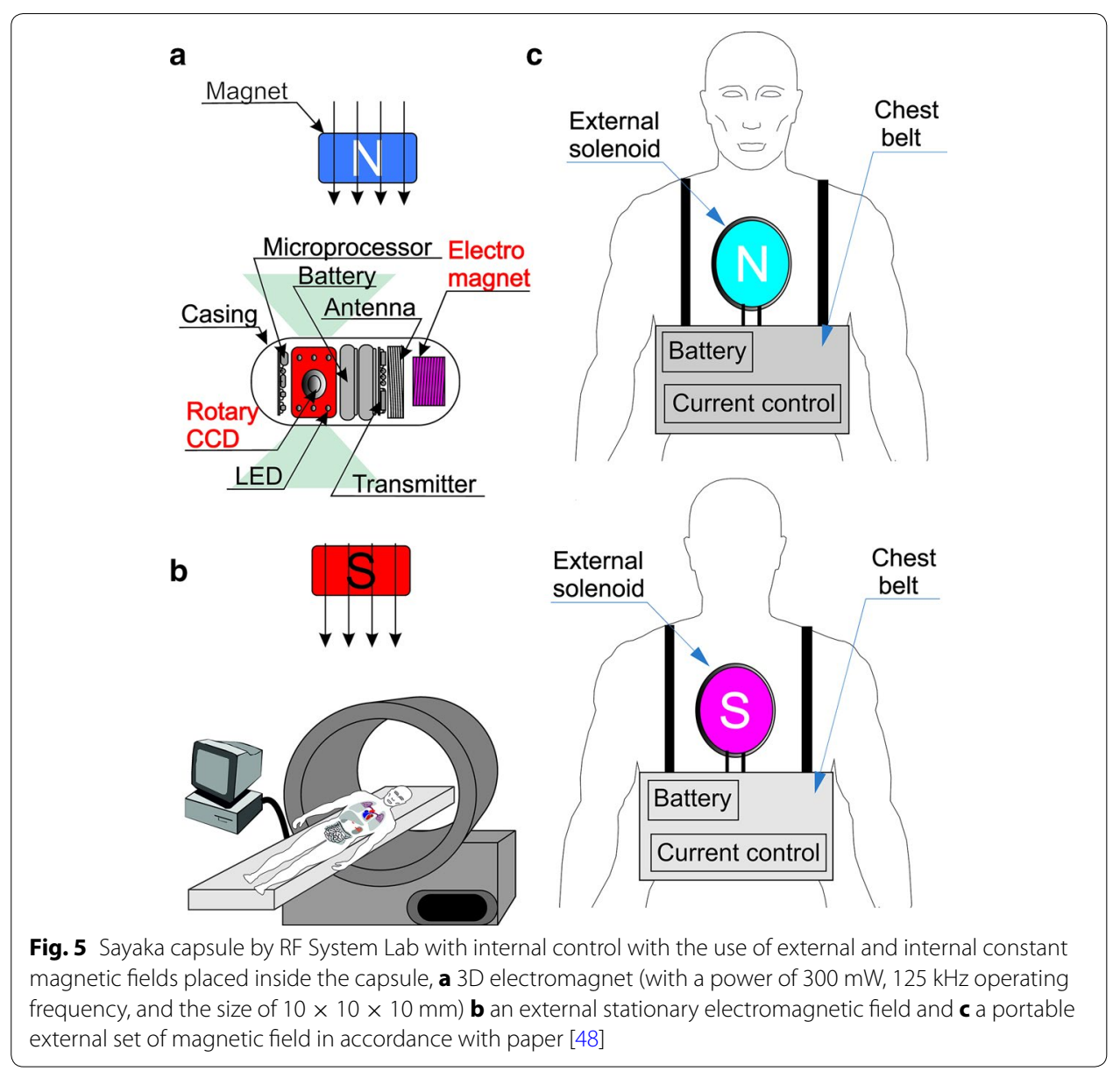


is used [50-54], for example, the so-called MGCE system which is the result of collaboration between Siemens Healthcare and Olympus Medical Systems Corporation. An electromagnetic assembly is in the form of a cylindrical roller inside which a patient is placed in the supine position-as in the case of tomography.

\section{Change of the imagining area}

The imaging area is very important in three-dimensional reconstruction, determination of the exact position of the capsule and, above all, determination of the size of visible objects (polyps, detachment, bowel perforation). For a typical camera position (Fig. 3), the imaging area in front of the capsule comprises an angle of about $170^{\circ}$ [55-58]. The angle is closely dependent on the lens and the casing type. However, the problem here is the accurate determination of the size of the observed objects because of the perspective-an unknown object distance from the camera. 3D and 4D reconstructions are performed [59-61] on the basis of the approximate information about the capsule movement speed, the positions of individual objects in the mage as well as changes and sizes along with the capsule movement. An alternative method is to place a rotatable camera or group of cameras transversely to the main axis of the capsule (Fig. 5a). Another way is to place capsules containing a conical mirror in the main axis, which allows for simultaneous observation of the full circumference of the intestine portion. All known types of deployment of cameras in capsules are shown in Fig. 6. The methods of image analysis and processing provide correct results in segmentation of specific areas such as the areas of bleeding. However, significant limitations directly associated with the place of imaging relate to the aspects of metrology. The greatest errors of up to several tens of percent are obtained during the assessment of the bleeding area size in capsules with a camera placed in their main axis (Fig. 6 a, b-Pill Cam SB/Colon). In the solution shown in Fig. 6c (Sayaka RF System Lab), the main problem is the dynamic error associated with the helical nature of imaging of specific portions of the intestine slice. The smallest acquisition errors (both dynamic and static ones) are obtained for the imaging methods shown in Fig. 6d, e. A few percent error values are for the solution d (CapsoCam SV-1). They are associated with the differences between CCDs of the four cameras. However, in the case of e) (Fig. 6e-RICE-National Chiao Tung University-[62]), they are associated with the non-axial embodiment of the conical mirror.

\section{Reducing the length of the capsule endoscopic video watched by a doctor}

A typical video from the capsule endoscopy examination lasts a few hours. Diagnosticians must watch the entire video to make a diagnosis because in typical clinical cases there is no indication in which bowel area they are to search for bleeding, tumours or other types of damage caused, for example, by non-steroidal anti-inflammatory drugs (NSAIDs) or radiotherapy. The capsule movements result from the impact of gravity and bowel movements. In the small intestine there are two types of contractions: (1) peristaltic and (2) staple (segment). The first type of contractions is responsible for the transit of food (relatively linear in nature), while the latter one is responsible for mixing food (rather chaotic). These movements are regularly punctuated by moments of relaxation in the intestinal muscles. The result is that the image obtained from capsule endoscopy is highly diverse-moments of stillness, the camera obscured by food debris, moments 


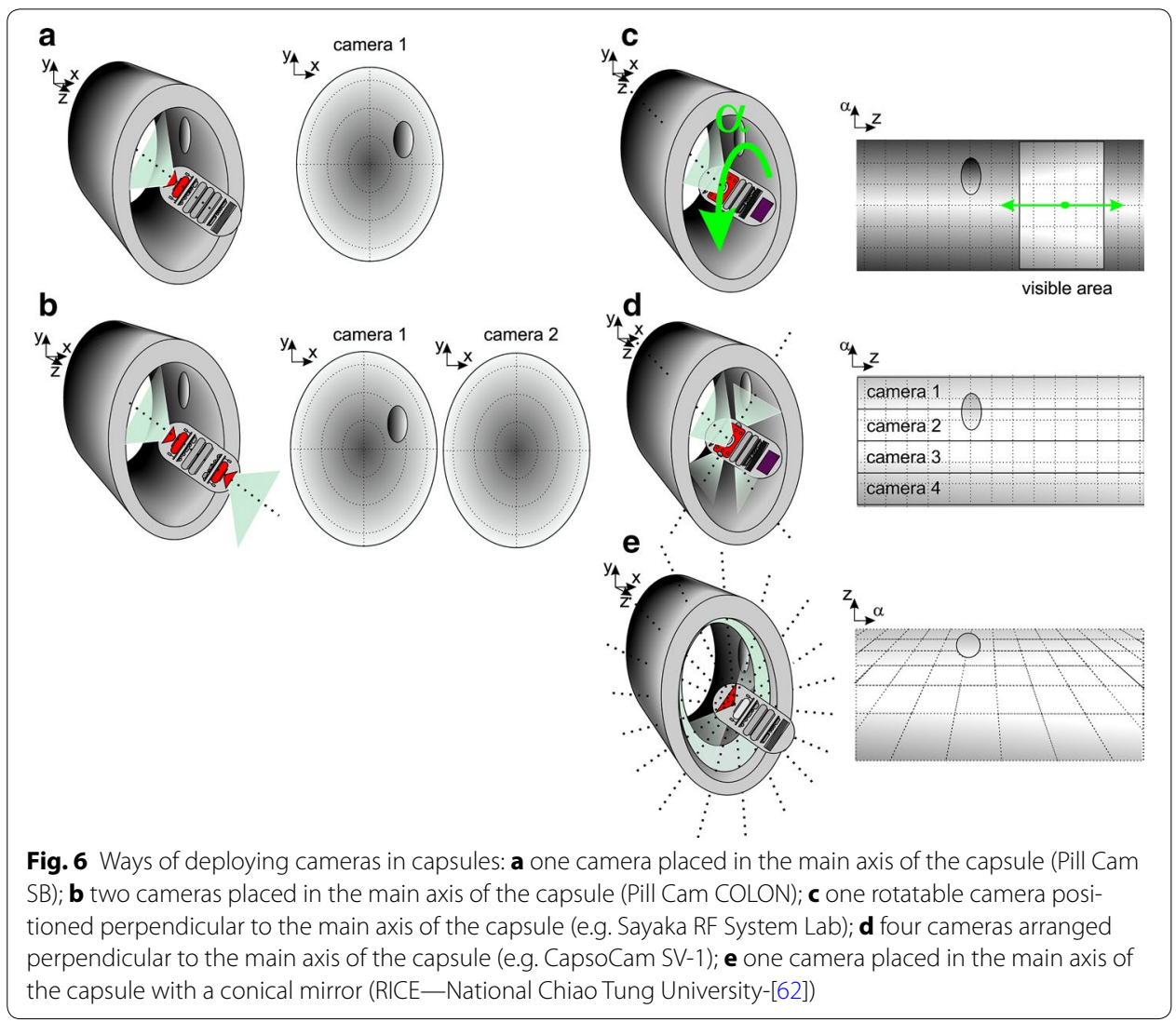

of dynamic movements and thereby changes of the imaging area. Therefore the video watched by a diagnostician requires acceleration, deceleration, and sometimes it must be watched frame by frame. Consequently, there is an ongoing research study related to the implementation of image analysis and processing methods allowing for automatic video analysis. The use of, for example, a model deformed for camera motion analysis and a universal method of feature selection and classification results in a much shorter video. In comparison to this, commercial software, for example, RapidReader (by GivenImaging) or free CapView, enables only to find the area of bleeding [63, 64]. Clinically, image analysis and processing such as the selection of image features [65, 66], colour-based segmentation [67], segmentation using vector classifiers and hidden markov models [68], discriminant analysis [69, 70] and others [71-74] allow for a significant reduction in analysis time. Moreover, mathematical morphology methods such as erosion, dilation, opening or closing as well as classical methods of binarization or wavelet analysis can be applied here. Particularly good segmentation results are also obtained for the HSV colour model which allows for precise determination and segmentation of the bleeding areas. According to publications [63-74] the video is shortened by more than $90 \%$. In clinical practice it means that medical diagnosticians watch a few minutes of the video including all the pathologies detected by the software.

Additional information stored in the memory is extremely useful in the evaluation and interpretation of the video. This is, for example, the current time which is saved for each video frame. Additionally, the patient is often asked to record abnormal situations 
related to the manual tasks performed during the test (i.e. sudden getting up, running or moving by means of some vehicle). These elements greatly improve interpretation of individual video frames and make it easier to identify a diagnostically interesting video fragment. In addition, in some systems there is the possibility to track the capsule position on the basis of the signal strength and by placing antennas on the patient [63-69].

According to the current state of knowledge, it seems that everything has been done. However, there are many interesting and clinically recognized areas such as the thematic area of biopsy, capsule movement control or the assessment of the possibility of doing surgery with the use of capsules. This is discussed in the next section.

\section{Prospects and expectations of capsule endoscopy}

The previous section presented typical standard techniques and endoscopic capsules commonly available in medical units. The new research area related to capsule endoscopy concerns two areas: (1) biopsy performance and (2) control of the capsule direction and speed of movement. In this area there are many interesting solutions which in the future can be successfully used on an everyday basis. Below there is an overview of this type of solutions indicating their advantages and disadvantages.

\section{Performance of biopsy}

Biopsy performance is associated with solving four issues: (1) the site of biopsy; (2) bringing the knife (cutting equipment) closer to the located site; (3) biopsy performance; (4) protection of the biopsy material. Location of the biopsy site is performed using a typical camera intended for the intestine diagnosis. Bringing the cutting knife closer is usually performed [75] using an external electromagnetic field-Fig. 7. Figure 7 shows cross-sections of two cylindrical magnetized rings. Without an external magnetic field (Fig. 7c) the slice chamber is closed. When applying the external magnetic field (Fig. 7a),

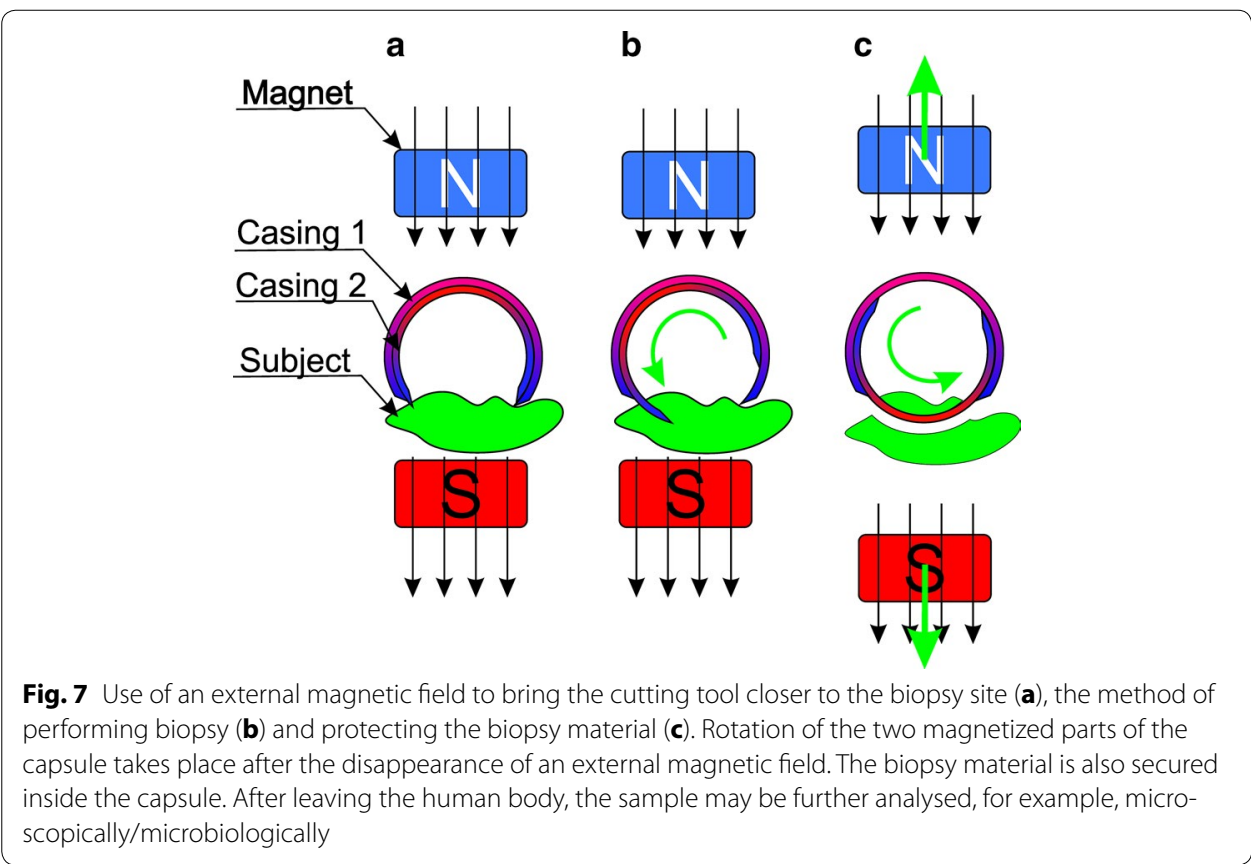


the rings are arranged in the direction of the external magnetic field thereby opening the chamber for biopsy performance and approaching the intestine. Removal of the external magnetic field (Fig. 7b) results in taking a sample and placing it in the chamber (Fig. 7c). Modifications of the described method apply to triggering the moment of samplingactivating the knife (knives). In addition to the discussed method which uses a magnetic field, it is also possible to take advantage of the energy stored in the spring-Fig. 8. Figure 8 shows sampling of an intestinal slice using an open chamber with a strained spring and then releasing the spring while taking the sample and securing it in the chamber [76]. The sample size is about $1 \mathrm{~mm}^{3}$ while the biopsy chamber in the described cases constitutes approximately 2, $3 \mathrm{~mm}$ of the capsule length. A significant problem that is currently being solved is that the site is not visible while sampling. There exist known solutions [77] in which the camera is placed in the capsule axis (as in Fig. 9) partly enabling visualization of the biopsy site. There are also solutions which involve the use of micro handles that are emptied from a special capsule tank. The grippers are made of metal with shape memory. Owing to the intestinal temperature, when they touch its wall they grip an intestinal slice and cut it. Micro grippers have a size of about $1 \times 2 \times 1 \mathrm{~mm}$ and are collected by the same capsule using adhesion forces [78]. The block diagram of this solution is shown in Fig. 10. Withdrawing micro grippers (using adhesion and cones) is not in this case too effective. With an external magnetic field controlling the capsule, the effectiveness is about $22 \%$, and with no external electromagnetic field it is only $3 \%$ [78]. In addition, the disadvantage of this solution is placing the camera on the opposite side relative to the cones which are designed to withdraw micro grippers.

a

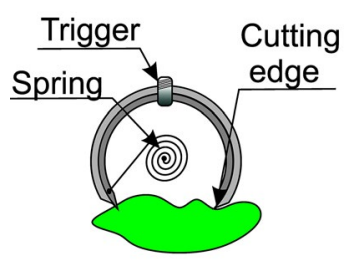

b

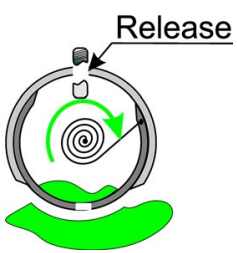

Fig. 8 Method for sampling of the intestine: a open chamber, strained spring, b releasing the spring with simultaneous sampling and storing the sample in the chamber. This solution enables to perform biopsy of a material (e.g. polyp) and secure it inside the capsule

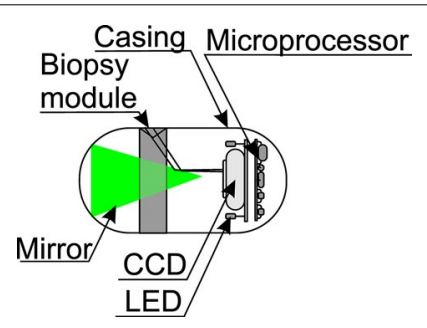

Fig. 9 Block diagram of the capsule containing a conical mirror (green) placed in its main axis and the biopsy module. The site of biopsy is directly visible to the camera. It is one of the biggest advantages of this solution (the possibility of simultaneous biopsy and observation of this portion in the camera) 


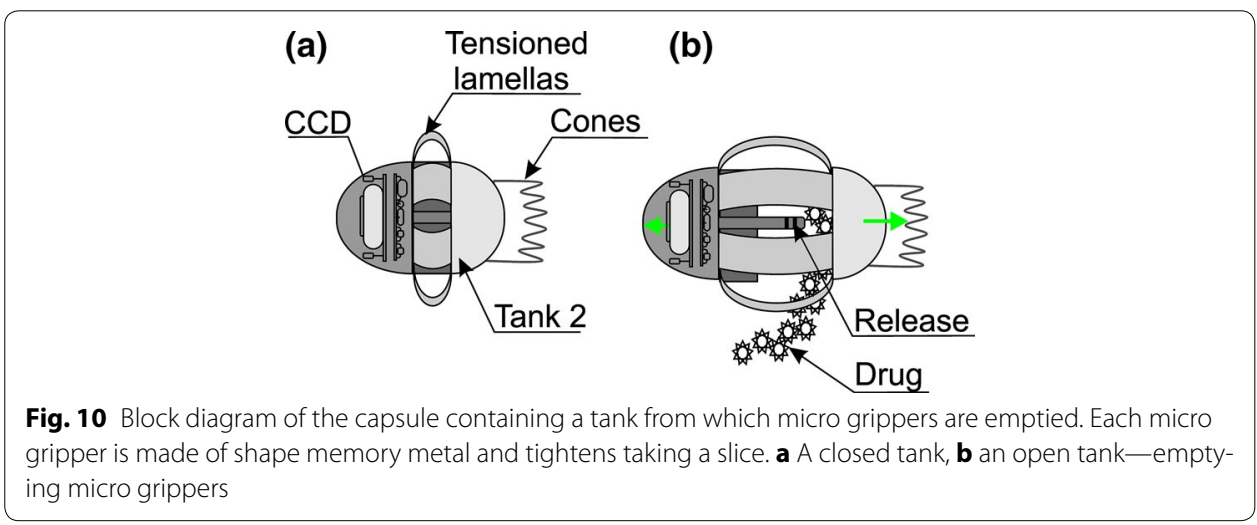

Nevertheless, it is one of the most interesting solutions proposed in recent years. These solutions, however, are still at the stage of clinical trials.

\section{Controlling the capsule movement}

The possibility of controlling the capsule movement is much more difficult technically. In this area, there are two known solutions which are being tested. One of them is related to placing servo-controlled legs, 4, 6 or 8 legs, depending on the solution, ensure the capsule movement speed of $0.5 \mathrm{~cm} / \mathrm{min}$ in both directions [79]. Figure 11 shows the block diagram of such a capsule. Controlling 2 independent leg assemblies is performed by using two independent actuators which include: a motor, gear, threaded rod, set of nuts, set of pins and legs (Fig. 11). It should be noted, however, that this solution does not contain important additional elements such as a camera or even a set of tanks for the drug.

The second solution involves placing motorized fins at the end of the capsule-Fig. 12 (Japanese Universities). However, such a solution (Fig. 12) has numerous drawbacks. The biggest drawback is the introduction of a mobile element (fin) that has a direct

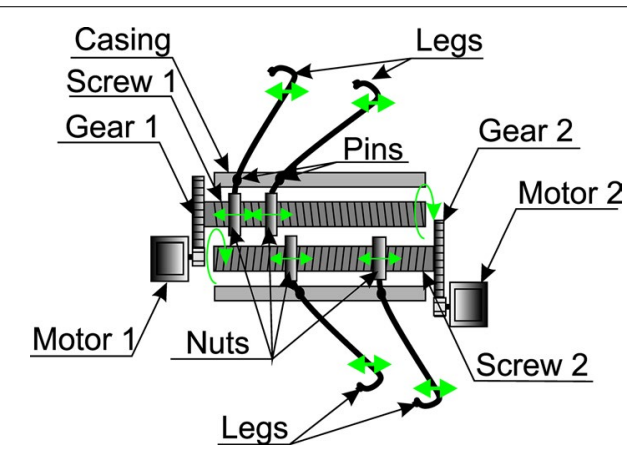

Fig. 11 Block diagram of the self-propelled capsule fitted with two sets of legs driven with two separate gear motors. The two motors which work independently drive threaded rods by means of the gears. These in turn allow for the movement of two sections of legs along the capsule. Depending on the number of legs, various parameters are obtained, which are associated with the arrangement of the intestine around the capsule and, therefore, its invasiveness and the possibility of the intestine perforation 


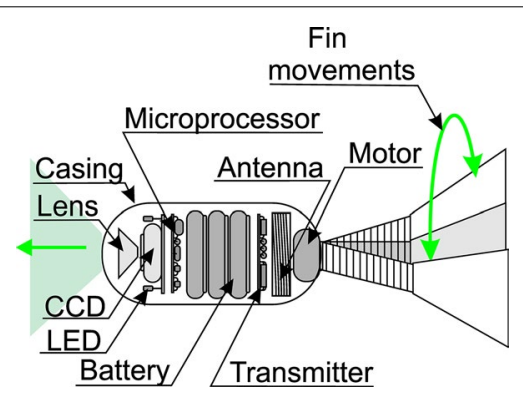

Fig. 12 Schematic diagram of the capsule with a drive in the form of fins. The motor placed at the end of the capsule drives the tail causing swinging movement. Both the frequency of movements and amplitude can be adjusted using the embedded microprocessor. The other elements, including the camera are placed in the usual way in the main axis of the capsule

contact with the surface (intestine). The fin size, depending on the solution, is about $10 \times 45 \mathrm{~mm}$. The obtained movement speed is $1 \mathrm{~cm} / \mathrm{s}$.

A different type of solution is represented by reconfigurable robots consisting of several capsules proposed in 2013 by Rama, Jason Pui, Ben Szewczyk and Yoo SeungSchik from Boston University. A patient swallows a few capsules that reconfigure in the patient's abdomen and are able to carry out any surgery. Each robot is comprised of a central capsule to which movable legs are automatically attached-Fig. 13. Problems that occur here are associated primarily with the fact that the capsules need to find one another and join together in the human digestive tract. Situations known from other previous solutions, for example, the possibility of bowel perforation during movement, are equally problematic.

The presented solutions of endoscopic capsules constitute the prospects and expectations related to the initially mentioned problems. Two of the most important problems are associated with:
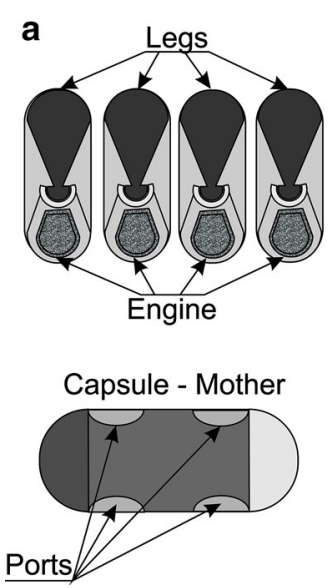

b

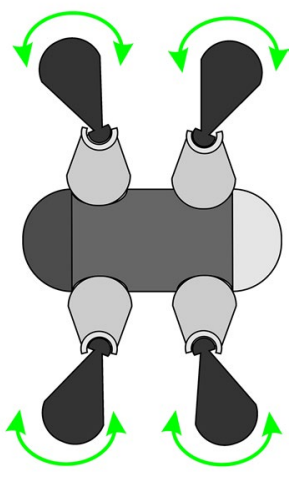

Fig. 13 Block diagram of $\mathbf{a}$ components of the robot constructed of five capsules, $\mathbf{b}$ the robot assembled inside the human body. The robot includes a "capsule mother" allowing for reconfiguration and connection of individual parts of the robot inside the human body. The patient swallows not one but a few capsules (parts of the robot), which are then combined and allow for various tasks in the human body (monitoring, biopsy, movement and others) 
movement in the intestine-using the external electromagnetic field (Fig. 5) or the capsule drive with the use of an external actuator (Figs. 11, 12);

performance of biopsy: using an external electromagnetic field (Fig. 8) or a self-propelled capsule (Fig. 10).

Only the methods of capsule control using an external electromagnetic field described in the previous section have been used in clinical practice. The other solutions (Figs. 7, 8, $9,10,11,12,13)$ are still at the stage of clinical trials and are not widely available.

\section{Clinical usefulness, limitations and possibilities of increasing the scope of capsule endoscopy}

The presented technical solutions are clinically useful and applied in varying degrees (as detailed previously). Most reports (99\% according to the Web of Science) refer to basic, most common types of endoscopic capsules (listed in Table 2). This also translates into the number of examined patients. For example, the number of patients examined with the use of capsule endoscopy by Given Imaging (PillCam: SB2, eso, colon) is 1.5 million to date, as declared by the company. The overview of Web of Science database for the year 2014 in the field of clinical reports enables to specify the information provided in Table 3.

The summary given in Table 3 shows that the total number of cases described in the clinical reports in 2014 exceeds 3000 . These are mostly works in the field of research with a high level of detail, for example, analysis of the impact of the chewing gum [85] or diet for children [87] prior to the use of capsule endoscopy. However, in 2014 most works were published as reviews in the area of capsule endoscopy. These works can be divided into typical overviews of capsule endoscopy (works [89-92] and [99]); (2) profiled review papers. In the second area (profiled review papers) the works on the impact of wireless data transmission on the operation of cardiac pacemakers [93], or the detection of bleeding, [88] and [95], are of interest [96-98]. The overview presented in work [94] concerns the analysis of practical usefulness of one of the new PillCam options, namely automatic adjustment of the number of registered frames to the rate of changes in the content of the observed area. To conclude, the data summarized in Table 3 and other works that have appeared in the area of capsule endoscopy in $2015[100,101]$ show:

1. Detection of polyps $>6 \mathrm{~mm}$ is at the level of $84-89 \%$ (for comparison, colonoscopy-100\%).

2. Intestinal cleanliness, when using standard methods is at the level of $78-81 \%$.

3. Diagnosis of Crohn's disease.

4. Identification of bleeding in the small intestine-effectiveness of 92.3, 44.2, and $12.9 \%$ for patients with ongoing-overt bleeding, obscure-occult bleeding, and past bleeding.

5. Recurrent oesophageal varices-effectiveness of 70-80 \%.

Undoubtedly, these great advantages of capsule endoscopy also have their limitations and resulting complications. These include: 
Table 3 Summary of the number of analysed cases and types of diagnosed diseases in clinical publications published in 2014

\begin{tabular}{|c|c|c|c|}
\hline Publication & $\begin{array}{l}\text { Number of } \\
\text { diagnosed cases }\end{array}$ & Type of disease & Results \\
\hline Laurain A. [82] & 80 & $\begin{array}{l}\text { Recurrent oesophageal } \\
\text { varices }\end{array}$ & $\begin{array}{l}\text { Capsule adequately classified } \\
77.5 \% \text { of the patients for } \\
\text { prophylaxis indication }\end{array}$ \\
\hline Jeon S. [83] & 2879 & $\begin{array}{c}\text { Cirrhosis patients with } \\
\text { portal hypertension }\end{array}$ & $\begin{array}{l}\text { The prevalence of PHE was } \\
40 \% \text {. Comparing the PHE } \\
\text { and non-PHE groups, the } \\
\text { most common findings were } \\
\text { angiodysplasias in } 55.7 \% \\
\text { and varices in } 38.9 \% \text {. Active } \\
\text { bleeding was observed in } \\
16.6 \text { and } 3.7 \% \text {, respectively }\end{array}$ \\
\hline Farnbacher M. [84] & 65 & Colorectal polyps & $\begin{array}{l}\text { At a } 30 \% \text { QV (QuickView) set- } \\
\text { ting, the QV video presented } \\
89 \% \text { of the significant polyps } \\
\text { and } 86 \% \text { of any polyps with } \\
\geq 1 \text { frame (per-polyp analysis) } \\
\text { identified in NM before. At a } \\
10 \% \text { QV setting, } 98 \% \text { of the } \\
52 \text { patients with significant } \\
\text { polyps could be identified } \\
\text { (per-patient analysis) by QV } \\
\text { video analysis }\end{array}$ \\
\hline Ou G. [85] & 6 & Impact of chewing gum & $\begin{array}{l}\text { Chewing gum did not have } \\
\text { any significant effect on } \\
\text { gastric transit time (rate ratio } \\
1.06 ; \mathrm{p}=0.75) \text {, small-bowel } \\
\text { transit time (rate ratio } 0.91 \text {; } \\
\mathrm{p}=0.65 \text { ), or completion rate } \\
\text { of capsule endoscopies }\end{array}$ \\
\hline Triantafyllou K. [86] & 75 & $\begin{array}{l}\text { Complementing } \\
\text { incomplete } \\
\text { colonoscopy }\end{array}$ & $\begin{array}{l}\text { One-third of the patients } \\
\text { underwent capsule endos- } \\
\text { copies immediately after } \\
\text { colonoscopy }\end{array}$ \\
\hline Oliva S. [87] & 198 & $\begin{array}{l}\text { Small bowel cleansing } \\
\text { by capsule endoscopy } \\
\text { addressed in children }\end{array}$ & $\begin{array}{l}\text { It supported the use of } 25 \mathrm{ml} / \\
\text { kg of polyethylene glycol } \\
\text { solution plus } 20 \mathrm{ml} \text { ( } 376 \mathrm{mg} \text { ) } \\
\text { of oral simethicone as the } \\
\text { preparation of choice for } \\
\text { capsule endoscopy }\end{array}$ \\
\hline
\end{tabular}

- capsule blockage in the small intestine-about $0.75 \%$ of all cases, $1.25 \%$ of patients with Crohn's disease [80, 81];

- problems with swallowing the capsule by the patient (in such cases the capsule is placed by means of endoscopy in the patient's stomach);

- lack of research in the last sections of the intestine in patients with sluggish bowel motion and the associated maximum capsule operating time $(8 \mathrm{~h})$-the problem occurs in about $33 \%$ of patients;

- no capsule control-lack of possibility of seeing the same area again (in the simplest and most popular solutions-Table 2);

- no possibility of sampling-biopsy. New solutions, mentioned in the previous section, are still not common, or are in the process of research;

- inability to perform simple operations. 


\section{New directions of research in the field of capsule endoscopy}

Some of the above disadvantages of capsule endoscopy constitute a new current research area which includes:

- ensuring capsule mobility inside the intestine without an external electromagnetic field-preferably in both directions. Various capsule prototypes have been developed in this respect, but there are significant difficulties in miniaturization and approval for general use $(4,6,8$ legs driven by two independent servos, or the capsule developed in Japanese Universities-Fig. 12);

- enabling the performance of simple operations, sewing or drug delivery. As for simple operations, a module of biopsy (discussed in the previous section) has been developed. Drug delivery and pH measurement are available in a capsule (iPill solution developed at Philips Research Laboratories), but this solution does not contain a CCD camera;

- adjusting a proper diet, type of fluids administered to a patient before the examination in such a way so as to get the most accurate images without interference of food debris while ensuring the best possible comfort of the patient;

- automating the software, preferably to such a form in which the algorithm would separate the interesting area, and then compare with the base of standard pathologies and give hints to the doctor. The hint would automatically indicate which video part is the most interesting, and how large the change (pathology) is in terms of quantity (not quality);

- using other wavelengths in the visible range (possibly outside the visible range) and analysis of results in the form of, for example, hyperspectral analysis.

Another interesting research area is the examination cost reduction. Currently, due to the cost, it must be first decided whether capsule endoscopy is really necessary, and then, if the capsule endoscopy examination affects clinical decisions. In paper [102] in a study of 128 patients with suspected colorectal pathological lesions, the results of capsule endoscopy in 94 patients did not affect previous clinical decisions. At the same time the authors of paper [102] emphasized the validity of the examination in patients who were to undergo surgery. In work [103] it was found that in $26 \%$ of patients (out of 300 examined) the result obtained from capsule endoscopy contributed to changing clinical measures. The group of patients included, in particular, those with unexplained bleeding. On the other hand, in work [104] the average cost of tests was analysed for 369 patients. It was found that the average cost of a positive diagnosis in patients who underwent capsule endoscopy was 2090.76 euros, and in those diagnosed by other methods-3828.83 euros. A reduction in the examination cost will be in the coming years a consequence of technological advancements, and thus miniaturization and universal access to endoscopic capsules.

\section{Restrictions on the use of capsule endoscopy}

The technology and specifics of the capsule operation still limit the application of capsule endoscopy. In particular, these limitations include: 
- problems with the local contamination of the capsule visual track. Despite doing the test under fasting conditions, local bubbles of fluids often prevent proper observation of the intestine [105]. The problem is too big to get rid of it completely. The only solution in these situations is to control the external magnetic field in order to clear the optical path or to omit local clusters of bubbles of fluids. However, it is possible to use an external magnetic field only in a medical facility, which increases the examination cost related to hospitalization and the need for continuous observation of the patient by a physician. At present, this problem is still not resolved;

- a problem with competing methods. Compared with competing methods, capsule endoscopy is used in a limited range of diagnostics, i.e.: in the diagnosis of unexplained bleeding and diagnosis of Crohn's disease. It is less effective in the diagnosis of other diseases (other methods: single-balloon enteroscopy, spiral enteroscopy, double-balloon enteroscopy give better results) [106];

- a problem with proper preparation of the patient's intestine for the test. This problem is related not only to the area of good vision of the camera mentioned before, but also to the responsibility of medical personnel for appropriate preparation of the patient for the examination (cleaning the intestine) and sometimes hospitalization (increase in the examination cost);

- no refund for this type of examination by the National Health Fund (NHF), the Food and Drug Administration (FDA). The availability of tests using capsule endoscopy in smaller towns in many EU countries and the USA is still limited [106];

- limited use. In fact, despite many solutions of capsule endoscopy presented above, it is still more or less accurate imaging (at various resolutions and with different numbers of cameras). There is no effective way to increase the range of use not only to enable biopsy of organs but also to perform any operations or even to stop the capsule in the intestine. Therefore, today endoscopy is still very limited to specific diagnostic purposes, basically one-detection of undisclosed bleeding from the small intestine [107];

- problems with the demonstration of statistically significant relevance and diagnostic sensitivity in detecting the small intestine or colon cancer [107]. This restriction is the reason why capsule endoscopy is not used interchangeably or even as a screening test in relation to classical colonoscopy [108];

- problems with ensuring economically justified further medical procedures (preparing the patient for the test again) after discovering irregularities in the patient's intestine. After detecting bleeding or any other abnormalities of the gastrointestinal tract, the patient is hospitalized and subsequent stages of clinical procedures are implemented-the patient must be prepared for surgery again, a medical appointment must be arranged and so on. The total number of treatments and medical procedures is greater when using capsule endoscopy. The only economic profit and greater patient's comfort are ensured when no irregularities are detected (lack of bleeding) [109];

- problems with limited operating time of capsules [110]. The operating time of $2-3 \mathrm{~h}$ is usually insufficient due to reduced intestinal motility. For this reason, the last section of the large intestine is not tested [111]. 


\section{Possibilities of increasing the scope of capsule endoscopy}

Despite these drawbacks, it is possible in the near future to increase the scope of capsule endoscopy by:

- increasing the camera (cameras) resolution. This translates into not only more accurate visualization of the intestine but also the possibility of replacing (after appropriate treatment) damaged or non-valid (obscured by bubbles of fluids lingering in the intestine) nearest video frames;

- increasing the operating time of capsules by enhancing battery capacity and/or reducing the power consumed by the image recording system of the capsule;

- reducing the diameter of the endoscopic capsule and integrating it with the patency capsule. This will allow the dissolution of the outer layer of the capsule and leaving the intestine in the case of its blockage. In addition, integration will reduce the cost of the test (using one capsule instead of two);

- increasing the sophistication of image analysis and classification of diseases. This will enable not only a further reduction in the length of the video examined by a physician but also detection of new bowel diseases whose diagnosis is currently impossible-e.g. colorectal cancer. Probably it will require three-dimensional reconstruction of trajectory of the capsule movement as well as acquisition of additional data related to the capsule movement;

- increasing the accuracy of measurement of the intestine damage or the size of polyps. In this respect, calibration of the measurement path as well as image analysis and processing are probably sufficient. The new direction of the measurement path calibration might necessitate, for example, adding to the capsule a module for laser evaluation of its distance from the intestinal walls;

- providing a new type of housing allowing for multiple use of the same capsule. Then it would be possible to introduce cheaper diagnostics in less densely populated areas where access to capsule endoscopy is limited or even impossible due to high costs;

- providing e-diagnostics. Currently, almost none of the producers of capsule endoscopy mention the possibility of remote interpretation of the recorded video-e-medical service. Universal access to smart mobile devices (smartphones, iPads) would ensure automatic contact with the doctor on duty and transmission of the video or its selected interesting frames (with automatic preliminary analysis of the video performed by means of the smartphone).

According to the author, all of these modifications can be introduced on the market in the next few years. They will increase the effectiveness of detection of additional bowel diseases, reduce the cost of treatment and the time of data analysis by the physician.

\section{Conclusions}

The current direction of research related to endoscopic capsules focuses on increasing their versatility and scope. In addition, it is important to reduce the burden on doctors analysing an endoscopic video. The following issues are also important here: (1) versatility in the reception of wireless data transmission from the capsule; (2) higher prevalence of capsules containing an internal non-volatile data memory; (3) reduction in the 
examination cost. The hope for capsule endoscopy is a new area of knowledge related to the methods of image analysis and processing as well as $3 \mathrm{D}$ modelling. Owing to the information about the image and the capsule position as well as human anatomical features, it is possible to perform fusion of data from different systems supporting the capsule operation. In particular, it can involve combining information about the capsule position with the acquired image and modelling a given organ-the intestine. This represents a new direction of research that already provides new diagnostic quality.

It now seems that endoscopic capsules which record the results directly in the internal flash memory (like CapsoCam SV-1) will gain the greatest popularity. If reading data did not require the use of an additional dock, in conjunction with the pilot capsule Agila, it would be a fully autonomous diagnostic kit (two capsules) that could be distributed in pharmacies. Remote diagnostics would be possible, for example, with the use of modern methods of medical telediagnostics. However, these solutions are still the future of capsule endoscopy. Still, given the advances in technology and miniaturization of the electronics, more sophisticated and miniaturized capsule endoscopy systems can be expected in the coming years. Technical possibilities of capsule endoscopy are constantly changing with the growth of technical progress and miniaturization of intelligent robots. The need to increase the accuracy of sensitivity and specificity in the detection of cancer and other diseases of the intestine still leaves an open area for microelectronics, electro-mechanics and computer science.

\footnotetext{
Abbreviations

VCE: video capsule endoscopy; WVE: wireless video endoscopy; CE: capsule endoscopy; WCE: wireless capsule endoscopy; WVC: wireless video capsule; RFID: radio-frequency identification.
}

Acknowledgements

No outside funding was received for this study.

Competing interests

The author declare that he have no competing interests.

Received: 29 May 2015 Accepted: 23 November 2015

Published online: 01 December 2015

\footnotetext{
References

1. Rajesh A, Sandrasegaran K, Jennings GS, Maglinte DDT, McHenry L, Lappas JC, Rex D. Comparison of capsule endoscopy with enteroclysis in the investigation of small bowel disease. Abdom Imaging. 2009;34(4):459-66.

2. Chiorean M. Capsule endoscopy in the evaluation of Crohn's disease. In: Rajesh A, Sinha R, editors. Crohn's Disease. Switzerland: Springer International Publishing; 2015. p. 33-46.

3. Boroff ES, Leighton JA. Capsule endoscopy in the evaluation of inflammatory bowel disease. In: Kozarek R, editor. Endoscopy in Inflammatory Bowel Disease. Seattle: Springer International Publishing; 2015. p. 105-20.

4. Rahman I, Patel P, Rondonotti E, Koulaouzidis A, Pennazio M, Kalla R, Sidhu R, Mooney P, Sanders D, Despott EJ, Fraser C, Kurniawan N, Baltes P, Keuchel M, Davison C, Beejay N, Parker C, Panter S. Small bowel capsule endoscopy. In: Li Z, Liao Z, editors. Handbook of capsule endoscopy. Dordrecht: Springer; 2014. p. 47-118.

5. Günther U, Bojarski Ch, Buhr HJ, Zeitz M, Heller F. Capsule endoscopy in small-bowel surveillance of patients with hereditary polyposis syndromes. Int J Colorectal Dis. 2010;25(11):1377-82.

6. Meister T, Heinzow HS, Domagk D, Dortgolz A, Lenze F, Ross M, Domschke W, Lügering A. Colon capsule endoscopy versus standard colonoscopy in assessing disease activity of ulcerative colitis: a prospective trial. Tech Coloproctol. 2013;17(6):641-6.

7. Sakai E, Endo H, Taguri M, Kawamura H, Taniguchi L, Hata Y, Ezuka A, Nagase H, Kessoku T, Ishii K, Arimoto J, Yamada E, Ohkubo H, Higurashi T, Koide T, Nonaka T, Takahashi H, Nakajima A. Frequency and risk factors for rebleeding events in patients with small bowel angioectasia. BMC Gastroenterol. 2014;14:1-9.

8. Nakamura M, Ohmiya N, Shirai O, Takenaka H, Morishima K, Miyahara R, Ando T, Watanabe O, Kawashima H, Itoh A, Hirooka Y, Goto H. Route selection for double-balloon endoscopy, based on capsule transit time, in obscure gastrointestinal bleeding. J Gastroenterol. 2010;45(6):592-9.
} 
9. Goto H. Diagnosis and treatment of small bowel diseases are advanced by capsule endoscopy and doubleballoon enteroscopy. Clin J Gastroenterol. 2010;3(5):219-25.

10. Rondonotti E, Franchis R. Capsule endoscopy: the answer to a challenge. In: Trecca A, editors. Ileoscopy. Italia: Springer-Verlag; 2012. p. 65-71.

11. Oliva S, Cohen S. Capsule endoscopy in pediatrics. In: Li Z, Liao Z, editors. Handbook of capsule endoscopy. Dordrecht: Springer; 2014. p. 145-151.

12. Rondonotti E, Pennazio M. Timing and protocols of endoscopic follow-up in operated patients after small bowel surgery. In: Galloro G, editors. Endoscopic follow-up of digestive anastomosis. Italia: Springer-Verlag; 2014. p. 41-8.

13. Postgate AJ, Burling D, Gupta A, Fitzpatrick A, Fraser C. Safety, reliability and limitations of the given patency capsule in patients at risk of capsule retention: a 3-year technical review. Dig Dis Sci. 2008;53(10):2732-8.

14. Koulaouzidis A, Douglas S, Plevris JN. Oesophageal capsule endoscopy. In: Li Z, Liao Z, editors. Handbook of capsule endoscopy. Dordrecht: Springer; 2014. p. 119-28.

15. Tolan DJM, Taylor SA, Halligan S. MRI of the small bowel: clinical role. In: Stoker J, editor. MRI of the gastrointestinal tract. Berlin: Springer-Verlag; 2010. p. 149-71.

16. Ciaccio EJ, Tennyson CA, Bhagat G, Lewis SK, Green PHR. Robust spectral analysis of videocapsule images acquired from celiac disease patients. Biomed Eng Online. 2011;10:78.

17. Ciaccio EJ, Tennyson CA, Bhagat G, Lewis SK, Green PHR. Quantitative estimates of motility from video capsule endoscopy are useful to discern celiac patients from controls. Dig Dis Sci. 2012;57(11):2936-43.

18. Leung LS, Nam WH, Chang S. In: Fine H, Mojon D, editors. Minimally Invasive Ophthalmic Surgery. Berlin: SpringerVerlag; 2010. p. 217-31.

19. Leighton JA, Watanabe K, Argüelles-Arias F, Gutiérrez JM. Video capsule endoscopy in suspected Crohn's disease. In: Keuchel M, Hagenmuller F, Tajiri H, editors. Video capsule endoscopy. Berlin: Springer-Verlag; 2014. p. 221-30.

20. Soto JA, Park SH, Fletcher JG, Fidler JL. Gastrointestinal hemorrhage: evaluation with MDCT. Abdom Imaging. 2015;40(5):993-1009

21. Hakim FA, Alexander JA, Huprich JE, Grover M, Enders FT. CT-enterography may identify small bowel tumors not detected by capsule endoscopy: eight years experience at Mayo Clinic Rochester. Dig Dis Sci. 2011;56(10):2914-9.

22. Alderlieste YA, Rauws EAJ, Mathus-Vliegen EMH, Fockens P, Dekker E. Prospective enteroscopic evaluation of jejunal polyposis in patients with familial adenomatous polyposis and advanced duodenal polyposis. Fam Cancer. 2013;12(1):51-6.

23. Wiarda BM, Mensink PBF, Heine DGN, Stolk M, Dees J, Hazenberg H, Stoker J, Woude CJ, Kuipers EJ. Small bowel Crohn's disease: MR enteroclysis and capsule endoscopy compared to balloon-assisted enteroscopy. Abdom Imaging. 2012;37(3):397-403.

24. Alderlieste YA, Bastiaansen BA, Mathus-Vliegen EMH, Gouma DJ, Dekker E. High rate of recurrent adenomatosis during endoscopic surveillance after duodenectomy in patients with familial adenomatous polyposis. Fam Cancer. 2013;12(4):699-706.

25. Esaki M, Matsumoto T, Yada S, Yanaru-Fujisawa R, Kudo T, Yanai S, Nakamura S, lida M. Factors associated with the clinical impact of capsule endoscopy in patients with overt obscure gastrointestinal bleeding. Dig Dis Sci. 2010;55:2294-301.

26. Esaki M, Matsumoto T. Case presentation: edematous lesions. In: Matsui T, Matsumoto T, Aoyagi K, editors. Endoscopy in the Diagnosis of Small Intestine Diseases. Japan: Springer; 2014. p. 19-23.

27. Matsumoto T, Esaki M, Kurahara K, Hirai F, Fuchigami T, Matsui T, lida M. Double-contrast barium enteroclysis as a patency tool for nonsteroidal anti-inflammatory drug-induced enteropathy. Dig Dis Sci. 2011;56(11):3247-53.

28. Sethi S, Cohen J, Thaker AM, Garud S, Sawhney MS, Chuttani R, Pleskow DK, Falchuk K, Berzin TM. Prior capsule endoscopy improves the diagnostic and therapeutic yield of single-balloon enteroscopy. Dig Dis Sci. 2014;59(10):2497-502.

29. Treves ST, Manfredi M. Pediatric Nuclear Medicine and Molecular Imaging. 2014:41:265-82.

30. Yachimski P, Hur C. Upper endoscopy in patients with acute myocardial infarction and upper gastrointestinal bleeding: results of a decision analysis. Dig Dis Sci. 2009;54(4):701-11.

31. Minc N. Encyclopedia of microfluidics and nanofluidics. New York: Springer; 2015. p. 1681.

32. Packer CD, Abdominal pain. In: Loue S, Sajatovic M, editors. Encyclopedia of Aging and Public Health. New York: Springer; 2008. p. 65-7.

33. Dijk CN. Ankle arthroscopy. Berlin: Springer-Verlag; 2014. p. 408.

34. Lui TH. Arthroscopic assisted correction of Hallux valgus deformity. In: Maffulli N, Easley M, editors. Minimally invasive surgery of the foot and ankle. London: Springer-Verlag; 2011. p. 109-22.

35. Sun T, Xie X. Wang Z. In: Sun T, Xie X, Wang Z, editors. Wireless power transfer for medical microsystems. New York: Springer; 2013. p. 145-68.

36. Mohseni K. Microsynthetic jets. In: Li D, editor. Encyclopedia of microfluidics and Nanofluidics. New York: Springer; 2008. p. 1354-9.

37. Adler SN, Hassan C, Metzger Y, Sompolinsky Y, Spada C. Second-generation colon capsule endoscopy is feasible in the out-of-clinic setting. Surg Endosc. 2014;28(2):570-5.

38. Kopáčová M, Bureš J, Vykouřil L, Hladík P, Šimkovič D, Jon B, Ferko A, Tachecí l, Rejchrt S. Intraoperative enteroscopy: ten years' experience at a single tertiary center. Surg Endosc. 2007;21(7):1111-6.

39. Nakamura T, Terano A. Capsule endoscopy: past, present, and future. J Gastroenterol. 2008;43(2):93-9.

40. Rana SS, Bhasin DK, Singh K. Colonic lesions in patients undergoing small bowel capsule endoscopy. Int J Colorectal Dis. 2011;26(6):699-702.

41. Iddan G, Meron G, Glukhovsky A, Swain P. Wireless capsule endoscopy. Nature. 2000;405(6785):417-417.

42. Costamagna G, Shah SK, Riccioni ME, Foschia F, Mutignani M, Perri V, Vecchioli A, Brizi MG, Picciocchi A, Marano P. A prospective trial comparing small bowel radiographs and video capsule endoscopy for suspected small bowel disease. Gastroenterology. 2002;123(4):999-1005. 
43. Pennazio M, Santucci R, Rondonotti E, Abbiati C, Beccari G, Rossini FP, De Franchis R. Outcome of patients with obscure gastrointestinal bleeding after capsule endoscopy: report of 100 consecutive cases. Gastroenterology. 2004;126(3):643-53.

44. Ell C, Remke S, May A, Helou L, Henrich R, Mayer G. The first prospective controlled trial comparing wireless capsule endoscopy with push enteroscopy in chronic gastrointestinal bleeding. Endoscopy. 2002;34(9):685-9.

45. Lewis BS, Swain P. Capsule endoscopy in the evaluation of patients with suspected small intestinal bleeding: Results of a pilot study. Gastrointest Endosc. 2002;56(3):349-53.

46. Koprowski R, Wilczyński S, Wróbel Z, Błońska-Fajfrowska B. Calibration and segmentation of skin areas in hyperspectral imaging for the needs of dermatology. Biomed Eng Online. 2014;13:113.

47. Koprowski R, Wilczyński S, Wróbel Z, Kasperczyk S, Błońska-Fajfrowska B. Automatic method for the dermatological diagnosis of selected hand skin features in hyperspectral imaging. Biomed Eng Online. 2014;13:47.

48. Martin P, Wu BT. Magnetic levitation of intraluminal microelectronic capsule. USA. Patent specification. US 8235055, B2. publ. 07.08.2012.

49. Ryu M, Kim JD, Chin HU, Kim J, Song SY. Three-dimensional power receiver for in vivo robotic capsules. Med Biol. Eng. Comput. 2007;45(10):997-1002.

50. Kummer MP, Abbott JJ, Kratochvil BE, Borer R, Sengul A, Nelson BJ. OctoMag: an electromagnetic systems for 5-DOF wireless micromanipulation. IEEE Trans. Robotics. 2010;26(6):1006-17.

51. Keller H, Juloski A, Kawano H, In: Proc. IEEE Int. Conf. on Biomedical Robotics and Biomechatronics. Method for navigation and control of a magnetically guided capsule endoscope in the human stomach. Rome, Italy. 2012 June 24-27. p. 859-65.

52. Yim S, Sitti M. Design and rolling locomotion of a magnetically actuated soft capsule endoscope. IEEE Trans Robot. 2012;28(1):183-94.

53. Lien G, et al. Magnetic control system targeted for capsule endoscopic operations in the stomach-design, fabrication, and in vitro and ex vivo evaluations. IEEE Trans Biomed Eng. 2012;59(7):2068-79.

54. Ciuti G, Valdastri P, Menciassi A. Robotic magnetic steering and locomotion of capsule endoscope for diagnostic and surgical endoluminal procedures. Robotica. 2010;28(2):199-207.

55. Koulaouzidis A, lakovidis GK, Karargyris A, Plevris JN. Optimizing lesion detection in small-bowel capsule endoscopy: from present problems to future solutions. Expert Rev Gastroenterol Hepatol. 2015;9(2):217-35.

56. Rondonotti E, Koulaouzidis A, Karargyris A, Giannakou A, Fini L, Soncini M, Pennazio M, Douglas S, Shams A, Lachlan N, Zahid A, Mandelli G, Girelli C. Utility of 3-dimensional image reconstruction in the diagnosis of smallbowel masses in capsule endoscopy (with video). Gastrointest Endosc. 2014;80(4):642-51.

57. Karargyris A, Rondonotti E, Mandelli G, Koulaouzidis A. Evaluation of 4 three-dimensional representation algorithms in capsule endoscopy images. World J Gastroenterol. 2013;19(44):8028-33.

58. Koulaouzidis A, Karargyris A. Use of enhancement algorithm to suppress reflections in 3-D reconstructed capsule endoscopy images. World J Gastrointest Endosc. 2013;5(9):465-7.

59. Koulaouzidis A, Karargyris A, Rondonotti E, Noble CL, Douglas S, Alexandridis E, Zahid AM, Bathgate AJ, Trimble KC, Plevris JN. Three-dimensional representation software as image enhancement tool in small-bowel capsule endoscopy: a feasibility study. Dig Liver Dis. 2013;45(11):909-14.

60. Neto FA, Ferreira MC, Bertoncello LC, Neto AA, de Aveiro WC, Bento CA, Cecchino GN, Rocha MA. Gastric lipoma presenting as a giant bulging mass in an oligosymptomatic patient: a case report. J Med Case Rep. 2012;6:317.

61. Koulaouzidis A, Karargyris A. Three-dimensional image reconstruction in capsule endoscopy. World J Gastroenterol. 2012;18(31):4086-90.

62. Ou-Yang M, Jeng WD. Design and analysis of radial imaging capsule endoscope (RICE) system. Opt Express. 2011;19(5):4369-83.

63. Capview. http://www.capview.org/. Accessed Jan 2015.

64. Cunha JS, Coimbra M, Campos P, Soares JM. Automated topographic segmentation and transit time estimation in endoscopic capsule exams. IEEE Trans Med Imaging. 2008;27(1):19-27.

65. Coimbra MT, Cunha JPS. MPEG-7 visual descriptors - contributions for automated feature extraction in capsule endoscopy. IEEE Trans Circuits Syst Video Technol. 2006;16(5):628-37.

66. Karargyris A, Bourbakis N. Wireless capsule endoscopy and endoscopic imaging: a survey on various methodologies presented. IEEE Eng Med Biol Mag. 2010;29(1):72-83.

67. Mackiewicz M, Berens J, Fisher M. Wireless capsule endoscopy color video segmentation. IEEE Trans Med Imaging. 2008;27(12):1769-81.

68. Mackiewicz MW, Berens J, Fisher M. Wireless capsule endoscopy video segmentation using support vector classifiers and hidden markov models. In: Proc. International Conference Medical Image Understanding and Analyses. 2006; p. 81-5.

69. Mackiewicz M, Berens J, Fisher M, Bell D. Colour and texture based gastrointestinal tissue discrimination, IEEE International Conference on Acoustics, Speech and Signal Processing, 2006. ICASSP 2006 Proceedings. 2006; 2(II).

70. Berens J, Mackiewicz MW, Bell GD. Stomach, intestine, and colon tissue discriminators for wireless capsule endoscopy images. In: Proceedings of SPIE, San Diego, CA, USA. 2005; pp. 283-90.

71. Vilarino F, Spyridonos P, Pujol O, Vitria J, Radeva P. Automatic detection of intestinal juices in wireless capsule video endoscopy, In: International Conference on Pattern Recognition 2006; vol. 4, p. 719-22.

72. Vilarino F, Kuncheva LI, Radeva P. ROC curves and video analysis optimization in intestinal capsule endoscopy. Pattern Recogn Lett. 2006;27(8):875-81.

73. Karargyris A, Bourbakis N. A video-frame based registration using segmentation and graph connectivity for wireless capsule endoscopy. Proceedings of the 2009 IEEE/NIH Life Science Systems and Applications Workshop (LiSSA 2009), IEEE/NIH. In: Proc. Life Science Systems and Applications Workshop, LiSSA 2009. Bethesda, MD, USA 2009. p. 74-9.

74. Coimbra M, Campos P, Cunha JPS. Extracting clinical information from endoscopic capsule exams using MPEG-7 visual descriptors. IEE Seminar Digests. 2005;11099:105-10. 
75. Simi M, Gerboni G, Menciassi A, Valdastri P. Magnetic torsion spring mechanism for a wireless biopsy capsule. J Med Devices. 2013;7(4):041009.

76. Kong K, Cha J, Jeon D, Cho DD. A rotational micro biopsy device for the capsule endoscopy. In: Proc. IEEE/RSJ International Conference on Intelligent Robots and Systems 2005: p. 1839-43.

77. Kong K, Yim S, Choi S, Jeon D. A robotic biopsy device for capsule endoscopy. J Med Devices. 2012;6(3):031004.

78. Yim S, Gultepe E, Gracias DH, Sitti M. Biopsy using a magnetic capsule endoscope carrying, releasing, and retrieving untethered microgrippers. IEEE Trans Biomed Eng. 2014;61(2):513-21.

79. Nusca A. New'spider pill' camera robots offer comfortable alternative to colonoscopy. http://www.smartplanet. com/blog/smart-takes/new-spider-pill-camera-robots-offer-comfortable-alternative-to-colonoscopy/. Accessed Jan 2015.

80. Hoog CM, Bark LA, Arkani J, Gorsetman J, Broström O, Sjöqvist U. Capsule retentions and incomplete capsule endoscopy examinations: an analysis of 2300 examinations. Gastroenterol Res Pract. 2012;2012. doi:10.1155/2012/518718

81. Liao Z, Gao R, Xu C, Li ZS. Indications and detection, completion, and retention rates of small-bowel capsule endoscopy: a systematic review. Gastrointest Endosc. 2010;71:280-6.

82. Laurain A, Gincul R, Vanbiervliet G, Bramli S, Heyries L, Martane G, Amrani N, Serraj I, Saurin JC, Borentain P, Filoche B, Duburque C, Gaudric M, Sogni P, Dumortier J. Oesophageal capsule endoscopy versus oesophago-gastroduodenoscopy for the diagnosis of recurrent varices: a prospective multicentre study. Dig Liver Dis. 2014;46(6):535-40.

83. Jeon SR, Kim JO, Kim JB, Chang YDK, Shim KN, Cheung DY, Kim JS, Choi MG, Song HJ, Lim YJ, Park SJ, Kim JH, Moon JS, Jeen YT. Portal hypertensive enteropathy diagnosed by capsule endoscopy in cirrhotic patients: a nationwide multicenter study. Dig Dis Sci. 2014;59(5):1036-41.

84. Farnbacher MJ, Krause HH, Hagel AF, Raithel M, Neurath MF, Schneider T. QuickView video preview software of colon capsule endoscopy: reliability in presenting colorectal polyps as compared to normal mode reading. Scand J Gastroenterol. 2014;49(3):339-46.

85. Ou G, Svarta S, Chan C, Galorport C, Qian H, Enns R. The effect of chewing gum on small-bowel transit time in capsule endoscopy: a prospective, randomized trial. Gastrointest Endosc. 2014;79(4):630-6.

86. Triantafyllou K, Viazis N, Tsibouris P, Zacharakis G, Kalantzis C, Karamanolis DG, Ladas SD. Colon capsule endoscopy is feasible to perform after incomplete colonoscopy and guides further workup in clinical practice. Gastrointest Endosc. 2014;79(2):307-16

87. Oliva S, Cucchiara S, Spada C, Hassan C, Ferrari F, Civitelli F, Pagliaro G, Di Nardo G. Small bowel cleansing for capsule endoscopy in paediatric patients: a prospective randomized single-blind study. Dig Liver Dis. 2014;46(1):51-5.

88. Tae CH, Shim KN. Should capsule endoscopy be the first test for every obscure gastrointestinal bleeding? Clin Endosc. 2014:47(5):409-14.

89. Colli A, Gana JC, Turner D, Yap J, Adams-Webber T, Ling SC, Casazza G. Capsule endoscopy for the diagnosis of oesophageal varices in people with chronic liver disease or portal vein thrombosis. Cochrane Database Syst Rev. 2014;10:CD008760.

90. Hale MF, Sidhu R, McAlindon ME. Capsule endoscopy: current practice and future directions. World J Gastroenterol. 2014;20(24):7752-9.

91. Singhal S, Nigar S, Paleti V, Lane D, Duddempudi S. Bowel preparation regimens for colon capsule endoscopy: a review. Therap Adv Gastroenterol. 2014;7(3):115-22.

92. Argüelles-Arias F, Rodríguez-Oballe J, Duarte-Chang C, Castro-Laria L, García-Montes JM, Caunedo-Álvarez A, Herrerías-Gutiérrez JM. Capsule endoscopy in the small bowel Crohn's disease. Gastroenterol Res Pract. 2014;2014:529136.

93. Bandorski D, Höltgen R, Stunder D, Keuchel M. Capsule endoscopy in patients with cardiac pacemakers, implantable cardioverter defibrillators and left heart assist devices. Ann Gastroenterol. 2014;27(1):3-8.

94. Kakugawa Y, Matsumoto M, Saito Y. Present conditions and future prospects of colon capsule endoscopy. Nihon Shokakibyo Gakkai Zasshi. 2014;111(3):464-9.

95. Nadler M, Eliakim R. The role of capsule endoscopy in acute gastrointestinal bleeding. Therap Adv Gastroenterol. 2014;7(2):87-92.

96. Kopylov U, Seidman EG. Role of capsule endoscopy in inflammatory bowel disease. World J Gastroenterol. 2014;20(5):1155-64

97. Munoz F, Alici G, Li W. A review of drug delivery systems for capsule endoscopy. Adv Drug Deliv Rev. 2014;71:77-85.

98. Kotwal VS, Attar BM, Gupta S, Agarwal R. Should bowel preparation, antifoaming agents, or prokinetics be used before video capsule endoscopy? A systematic review and meta-analysis. Eur J Gastroenterol Hepatol. 2014;26(2):137-45.

99. Soga K, Handa O, Yamada M, Sakagami J, Yagi N, Naito Y, Yoshikawa T, Itoh Y, Arizono N. In vivo imaging of intestinal helminths by capsule endoscopy. Parasitol Int. 2014;63(1):221-8.

100. Imagawa H, Ikemoto J, Kanemitu K, Teraoka Y, Izumi Y, Nakadoi K, Okazaki A, Katamura Y, Shinzato M, Onogawa S, Hirano N, Hanada K, Amano H, Hino F. A trial of the use of patency capsules in combination with overnight capsule endoscopy. Digestion. 2015;91(1):46-9.

101. Hale MF, Rahman I, Drew K, Sidhu R, Riley SA, Patel P, McAlindon ME. Magnetically steerable gastric capsule endoscopy is equivalent to flexible endoscopy in the detection of markers in an excised porcine stomach model: results of a randomized trial. Endoscopy. 2015:47(7):650-3.

102. Gubler C, Fox M, Hengstler P, Abraham D, Eigenmann F, Bauerfeind P. Capsule endoscopy: impact on clinical decision making in patients with suspected small bowel bleeding. Endoscopy. 2007;39(12):1031-6.

103. Sidhu R, Sanders DS, Kapur K, Hurlstone DP, McAlindon ME. Capsule endoscopy changes patient management in routine clinical practice. Dig Dis Sci. 2007;52(5):1382-6.

104. Marmo R, Rotondano G, Rondonotti E, de Franchis R, D'Incà R, Vettorato MG, Costamagna G, Riccioni ME, Spada C, D’Angella R, Milazzo G, Faraone A, Rizzetto M, Barbon V, Occhipinti P, Saettone S, laquinto G, Rossini FP. Capsule 
enteroscopy vs. other diagnostic procedures in diagnosing obscure gastrointestinal bleeding: a cost-effectiveness study. Eur J Gastroenterol Hepatol. 2007;19(7):535-42.

105. Pennazio M, Spada C, Eliakim R, Keuchel M, May A, Mulder CJ, Rondonotti E, Adler SN, Albert J, Baltes P, Barbaro F, Cellier C, Charton JP, Delvaux M, Despott EJ, Domagk D, Klein A, Alindon M, Rosa B, Rowse G, Sanders DS, Saurin JC, Sidhu R, Dumonceau J-M, Hassan C, Gralnek IM. Small-bowel capsule endoscopy and device-assisted enteroscopy for diagnosis and treatment of smallbowel disorders: European Society of Gastrointestinal Endoscopy (ESGE) Clinical Guideline. Endoscopy. 2015;47:352-76.

106. Medical Devices, Shine a light: the capsule endoscopy systems market, 29 September 2013. http://www medicaldevice-developments.com/features/featureshine-a-light-the-capsule-endoscopy-systems-market/.

107. Triantafyllou K, Beintaris I, Dimitriadis GD. Is there a role for colon capsule endoscopy beyond colorectal cancer screening? A literature review. World I Gastroenterol. 2014;20(36):13006-14.

108. Given Imaging Receives FDA Clearance for PillCam ${ }^{\circledR}$ COLON in Patients Following Incomplete Colonoscopy. http://www.givenimaging.com/en-us/Innovative-Solutions/Capsule-Endoscopy/pillcam-colon/Pages/COLONPress-release.aspx, Accessed Sep 2015.

109. Sieg A. Colon capsule endoscopy compared with conventional colonoscopy for the detection of colorectal neoplasms. Expert Rev Med Devices. 2011;8(2):1-5.

110. Spada C, Barbaro F, Andrisani G, Grazioli LM, Hassan C, Costamagna I, Campanale M, Costamagna G. Colon capsule endoscopy: what we know and what we would like to know. World J Gastroenterol. 2014;20(45):16948-55.

111. Tal AO, Vermehren J, Albert JG. Colon capsule endoscopy: current status and future directions. World J Gastroenterol. 2014;20(44):16596-602.

\section{Submit your next manuscript to BioMed Central and we will help you at every step:}

- We accept pre-submission inquiries

- Our selector tool helps you to find the most relevant journal

- We provide round the clock customer support

- Convenient online submission

- Thorough peer review

- Inclusion in PubMed and all major indexing services

- Maximum visibility for your research

Submit your manuscript at 